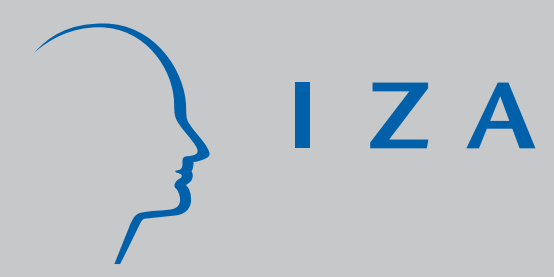

IZA DP No. 1890

Affect as a Source of Motivation in the Workplace:

A New Model of Labor Supply, and New Field Evidence on Income Targeting and the Goal Gradient

Lorenz Goette

David Huffman

December 2005 


\title{
Affect as a Source of Motivation in the Workplace: A New Model of Labor Supply, and New Field Evidence on Income Targeting and the Goal Gradient
}

\author{
Lorenz Goette \\ University of Zurich, CEPR \\ and IZA Bonn \\ David Huffman \\ IZA Bonn
}

\section{Discussion Paper No. 1890 \\ December 2005}

\author{
IZA \\ P.O. Box 7240 \\ 53072 Bonn \\ Germany \\ Phone: +49-228-3894-0 \\ Fax: +49-228-3894-180 \\ Email: iza@iza.org
}

\begin{abstract}
Any opinions expressed here are those of the author(s) and not those of the institute. Research disseminated by IZA may include views on policy, but the institute itself takes no institutional policy positions.
\end{abstract}

The Institute for the Study of Labor (IZA) in Bonn is a local and virtual international research center and a place of communication between science, politics and business. IZA is an independent nonprofit company supported by Deutsche Post World Net. The center is associated with the University of Bonn and offers a stimulating research environment through its research networks, research support, and visitors and doctoral programs. IZA engages in (i) original and internationally competitive research in all fields of labor economics, (ii) development of policy concepts, and (iii) dissemination of research results and concepts to the interested public.

IZA Discussion Papers often represent preliminary work and are circulated to encourage discussion. Citation of such a paper should account for its provisional character. A revised version may be available directly from the author. 


\section{ABSTRACT \\ Affect as a Source of Motivation in the Workplace: A New Model of Labor Supply, and New Field Evidence on Income Targeting and the Goal Gradient}

In this chapter we propose a new, dual-process model of labor supply, which incorporates both cognitive and affective aspects of decision-making. Consistent with evidence from neuroscience, the worker may experience conflicting cognitive and affective motivations during the workday. In particular, the affective system values effort more highly as long the worker's performance is below a personal goal, or income target, and becomes increasingly aroused as the goal approaches. As a result, affect can distort effort decisions relative to a fully cognitive benchmark, in a way that is consistent with evidence on loss aversion, and with the so-called goal-gradient effect, a tendency for animals and humans to increase effort as a goal approaches. In contrast to a standard model of labor supply, our model can predict a goal gradient, and predicts that workers may actually lower total daily effort in response to a temporary increase in the wage. Also, within-day windfall gains may have an impact on a worker's effort profile over the workday. The second part of the chapter tests this latter prediction using data from two bicycle messenger firms. At both firms, a windfall gain in the morning has the predicted impact. A lucky messenger works harder than other messengers over the first part of the afternoon, and the difference is increasing, consistent with a goal gradient. Later in the afternoon, a lucky messenger works significantly less hard than the others, consistent with having surpassed a personal earnings goal earlier in the day and having less affective motivation.

JEL Classification: J22, L2, B49

Keywords: affect, emotion, labor supply, loss aversion, income targeting, goal gradient

Corresponding author:

David Huffman

IZA

P.O. Box 7240

53072 Bonn

Germany

Email: huffman@iza.org 


\section{Introduction}

Until recently, decision research assumed that the primary source of human motivation was cognitive. In this framework, motivation to pursue a goal, or reward, is modeled as the outcome of a conscious calculation, in which the individual chooses the course of action with the highest net benefit.

By contrast, new evidence points to the importance of affect as a source of motivation. ${ }^{1}$ Experiments show that humans (and other animals) tend to evaluate performance on a task relative to a reference level, or goal, and experience affect as they make progress, or fail to make progress, towards this goal. This affective reaction has an impact on behavior. In particular, affect apparently explains loss aversion, a strong preference for not falling short of a reference point or goal, which acts as a psychological incentive to exert effort as long as the individual is below the goal. The tendency for affect to become increasingly intense, as distance from a goal decreases, can explain the so-called "goal gradient effect," the tendency for humans, rats, and other animals to increase effort as a goal draws nearer.

This chapter considers the impact of affect on motivation in the workplace. Because the standard model of labor supply is purely cognitive, and assumes that workers are only motivated by financial incentives, the first part of the chapter develops an alternative model that incorporates affect as an additional source of motivation. The key

\footnotetext{
${ }^{1}$ This chapter was written for both a psychology and economics audience. Were it is appropriate we define terms that may be unfamiliar to researchers in either discipline. For example, we use the term emotion as it is used in psychology, to refer to a specific feeling state, such as anger, sadness, joy, etc. In all other cases we use the more general term from psychology, affect.
} 
feature of the model is that affect, aroused by performance relative to a goal, can override the priorities assigned by cognitive decision-making and distort the worker's effort profile. Affect is assumed to respond to the immediacy of a goal or reward, increasing in intensity, and creating a stronger impulse to exert effort, as a goal draws near. We formalize this tension between affect and cognition in similar way to Loewenstein and O’Donoghue (2005), by assuming a two-part objective function for the individual, where one part corresponds to the preferences of the forward-looking, cognitive self, and the other to the more-myopic process that drives affective impulses.

We show that our model generates a psychological incentive to not fall short of a goal, consistent with experimental evidence on loss aversion, and predicts an increasing effort profile leading up to a goal, consistent with experimental evidence on the goal gradient effect. The model also predicts that a temporary increase in productivity, e.g. a temporary wage increase, may lead to lower total effort on a workday, because it causes an individual to reach the goal more quickly and thus removes some of the motivation arising from affect earlier in the day. This finding is at odds with a central prediction of the standard model, that workers should work harder when productivity, or the wage, is temporarily high. On the other hand it is consistent with a recent empirical literature focusing on occupations where workers are free to vary effort over the workday. The key stylized fact from this literature is that a worker's total daily effort is typically unchanged, or even decreases, on days when the wage is temporarily high (for a review see Goette, Huffman, and Fehr, 2004).

The second part of the chapter presents new empirical evidence on the relevance of affect for worker performance, using data from a real work setting where workers face 
strong financial incentives. Our data come from two bicycle messenger firms, and allow us to observe the within-day effort profiles of individual messengers. Bicycle messengers are attractive subjects for study because they have relative freedom to choose their effort. It is also important that luck plays a significant role in determining their daily earnings: messengers are paid a piece rate, and can earn substantially more or less than expected on a given day simply because they were lucky and obtained an attractive assignment.

Our strategy is to see how good luck or bad luck (windfall gains or losses) early in the day affect effort profiles later in the day. The standard model predicts that within-day windfall gains should have no impact on effort. By contrast, the affect-based model predicts that windfall gains in the morning can have a significant impact on the effort profile over the afternoon. A lucky morning can position a messenger quite close to the goal by the first hours of the afternoon, with the result that the goal gradient takes effect earlier, and messenger works harder, compared to other messengers. Later in the afternoon, when other messengers are getting close to their goals, the lucky messenger has already achieved the goal and thus works less hard. In fact, we find exactly this pattern, at both firms: afternoon effort is positively correlated with a windfall gain in the morning over the first few hours of the afternoon, but negatively correlated with a windfall gain in the morning over the final hours of the day. We also conducted a complementary survey with bicycle messengers, in which we asked directly about the importance of a daily earnings goal for motivation to exert effort, and find additional evidence supporting the alternative model of labor supply.

These findings contribute to the recent empirical literature on labor supply and loss aversion, which builds on the finding, already mentioned, that total daily effort 
sometimes decreases in response to a wage increase. The seminal paper in this literature, Camerer et al. (1997), studied New York City cab drivers and argued that the tendency for cabbies to work short hours on high wage days reflects loss aversion around a daily income target. More recently, Fehr and Goette (2002) conducted a field experiment in which bicycle messengers were given a higher wage for one month, and found that messengers decreased effort during shifts in this month. The decrease was strongest for messengers who were loss averse, as measured by a lottery experiment. This chapter extends the income-targeting hypothesis by emphasizing the affective underpinnings of loss aversion, and by building a dynamic model of progress towards a daily goal that incorporates another aspect of affective evaluation, namely immediacy. The model can predict a decrease in daily effort due to an increase in the wage (productivity), consistent with previous findings, but also generates a new prediction linking income targeting to affect, i.e. the goal gradient, which is testable using our data on within-day effort profiles. Importantly, this strategy avoids some of the concerns raised about interpretation of the findings in Camerer et al. (1997), and provides new support for the income-targeting hypothesis. $^{2}$

The broader theme of this volume is whether affect leads to better or worse decisions by individuals. We discuss this question in the conclusion of the chapter, after presenting our empirical results. The chapter is organized as follows. Section 2 describes the standard economic model of labor supply, and proposes an alternative model

\footnotetext{
${ }^{2}$ E.g. in Camerer et al. and other cab driver studies it is not clear whether wage variation is exogenous to effort choices. For a discussion of this point see Fehr and Goette (2002) and Farber (2005).
} 
incorporating affect. Section 3 describes the data and empirical design. Section 4 presents the empirical results. Section 5 concludes.

\subsection{Cognition and Affect in Daily Labor Supply}

\subsection{Standard model of labor supply}

The standard economic model captures the deliberative side of human decision-making. In the context of labor supply, the worker's decision consists of a forward-looking calculation of the costs and benefits of different possible effort profiles.

In this chapter we are mainly interested in the effort profile over the afternoon, conditional on morning earnings, so we write the worker's decision problem accordingly. We divide an afternoon $k$ into $m$ work episodes of length $\Delta$ and adopt the convention that episode $t$ lasts from $t$ to $t+\Delta$ on day $k$. We also assume utility is separable across work episodes. The worker's problem is then the following:

$$
\underset{e_{t}}{\operatorname{Max}} V_{t}=\lambda\left(w_{k} e_{t}+z_{t}\right)-c\left(e_{t}\right)
$$

Where $\lambda$ is the utility generated by an additional dollar of lifetime income, ${ }^{3}$ earnings in period $t$ are given by the product of the wage $w_{k}$ and effort $e_{t}$, and $z_{t}$, is income unrelated to effort in episode $t$, e.g., earnings from previous episodes during the day. The function $c()$ captures the cost of effort in terms of utility and is assumed to be convex.

Importantly, small changes in $z_{t}$, due to windfall gains or losses within a day do not interact with effort in the utility function, and thus do not have an impact on

\footnotetext{
${ }^{3}$ The worker is assumed to be forward looking, and thus to value income in terms of its value fur purchasing utility during the whole future lifetime.
} 
afternoon effort. The only channel through which windfall gains could interact with effort would be through $\lambda$, but $\lambda$ is constant with respect to small windfall gains. ${ }^{4}$ We test this prediction later in the chapter, in our empirical analysis.

The optimal effort level in hour $t$ is the amount of effort such that the extra benefit from exerting another unit of effort is just offset by the extra cost of that unit. Formally, the optimal level solves the following first order condition:

$$
c^{\prime}\left(e_{t}\right)=\lambda w_{t}
$$

Where c'() is the reduction in utility caused by exerting an extra unit of effort and $\lambda w_{t}$ is the increase in utility from an additional unit of labor earnings. This condition implies that an increase in financial incentives, $w_{t}$, leads to an increase in effort, limited by how quickly effort costs increase. Importantly, windfall gains and losses in the morning, which enter the period utility function (1) through $z_{t}$, do not enter the first order condition (2) and thus have no impact on the choice of hourly effort in the afternoon.

\subsection{Incorporating affect into a model of labor supply}

Evidence on the role of affect and cognition in decision-making

\footnotetext{
${ }^{4}$ Intuitively, the insensitivity of $\lambda$ to small $z_{t}$ follows from the assumption that the worker plans ahead for his or her future lifetime. With this time horizon in mind, the worker uses any windfall gain in earnings to increase consumption of leisure, and reduce work effort, by a small amount in every future period. Given that a lucky morning leads to a change in $z_{t}$ that is very small relative to total lifetime income, the resulting change in effort in any single future period will be essentially zero.
} 
Recent research in neuroscience provides groundwork for understanding the roles of cognition and affect in determining individual motivation. A key finding is that cognition and affect are governed by distinct neural systems in the brain (for an overview see Cohen, 2005).

Cognition takes place in the prefrontal cortex, the brain structure that developed most dramatically in the time since human evolution departed from that of the apes (Manuck et al., 2003). This cognitive system allows humans to consider the broader consequences of their actions, and corresponds to the deliberative, forward-looking self typically assumed in economic models. Affect stems from a group of evolutionarily older brain structures, which predate the capacity for cognitive thought and are found in a variety of other animal species in addition to humans (Massey, 2002; MacLean, 1990). The affective system is an engine for motivation in the service of survival, responding quickly to cues in the environment with situation-appropriate drives: hunger, anger, fear, sexual desire, etc.

An important implication of the dual-process structure of the brain is the possibility for conflicting motivations. Conflict can occur because the survival-oriented affective system has a relatively "conservative” set of pre-programmed priorities, which may ignore some of the broader, long-term considerations that inform cognitive decisionmaking.

One example of the affective system's conservatism is a tendency to prioritize immediate rewards and threats over longer-term considerations. A famous series of studies in psychology demonstrates the impact of immediacy on impulsive behavior, by showing that subjects are more likely to choose a small, immediate reward over a larger, 
delayed reward if the immediate reward is visible at the time of the decision (Mischel et al., 1972; Mischel et al., 1989; Mischel et al., 2003) More recently, McLure et al. (2005) find evidence suggesting that the cognitive system of the brain is involved in making intertemporal tradeoffs in general, but that the affective system is activated only when the tradeoff involves an immediate reward. The relative strength of activation of these two systems predicts whether the individual chooses an immediate reward or waits for the larger, delayed reward.

The affective system is also conservative when it comes to the possibility of losses. Choice experiments reveal that many people exhibit reference-dependent valuation, defining outcomes in terms or gains or losses relative to a reference level. In these evaluations, people tend to be loss averse, disliking losses more than they like gains of the same amount (for a review of evidence on reference dependence see Tversky and Kahneman, 2000). This reference-dependence, and asymmetry with respect to losses, makes sense as a survival strategy, in the sense that survival is as an exercise in staying above a critical threshold. Shiv et al. (2005) provide evidence that loss aversion is in fact generated by the affective system of the brain. They conduct a choice experiment involving real-stakes lotteries, in which the subjects include individuals with damage to the ventro-medial prefrontal cortex, a brain region involved in processing affect. Shiv et al. find that normal subjects display loss aversion, but the brain-damaged patients do not. Chen et al. (2005) provide further evidence that loss aversion is seated in the evolutionarily structures of the brain, which humans and monkeys have in common, by showing that capuchin monkeys exhibit loss aversion. 


\section{Affect and task motivation}

A number of studies provide direct evidence on the importance of affect for motivating task effort. Consistent with the myopic, reference-dependent character of the affective system, affect is found to play a role mainly when an individual has a goal or reference point in mind, and when the individual is close to achieving that goal. The resulting effort profile involves higher overall effort below a goal, with an increasing "goal gradient” in effort up until the point when the goal is achieved.

A study by Heath, Larrick and Wu (1999) finds evidence that goals act as reference points, and that affect provides a source of motivation to achieve goals, in a way that is consistent with loss aversion and the goal gradient. Heath, Larrick, and Wu posed subjects with the following hypothetical scenario:

Sally and Trish both follow workout plans that usually involve doing 25 sit-ups. One day, Sally sets a goal of performing 31 sit-ups. She finds herself very tired after performing 35 sit-ups and stops. Trish sets a goal of performing 39 sit-ups. She finds herself very tired after performing 35 sit-ups and stops. Who is experiencing more emotion?

Most subjects indicate that Trish, who is below her goal, is experiencing more emotion than Sally who is above her goal by the same amount [Trish, 71\%; Sally, 29\%; N=48]. This is consistent with the goal acting as a reference point and triggering the type of affective response, discussed above, that appears to play a role in explaining loss aversion. In another question, Heath, Larrick and Wu describe a similar situation, but ask who will exert more effort to do one more sit-up. Again, the question is careful to hold previous effort constant. Most subjects indicate that the individual below the goal will exert more effort than the individual who has surpassed the goal, consistent with loss aversion serving as a source of motivation [Above goal, $82 \%$; Below goal, 18\%; $\mathrm{N}=73$ ]. 
Finally, Heath, Larrick and Wu ask a question in which two individuals have completed the same number of sit-ups, and are both below their goal, but have different goals. Consistent with the goal gradient, and an increasing role for affect as a goal draws near, subjects indicate that the individual with the closer goal will work harder to perform one additional sit-up [Close to goal, 86\%; Far from goal, 14\%; N=74].

The first behavioral evidence of a goal gradient was observed in studies using animals. The seminal empirical study on the goal gradient was Hull (1934), which showed that rats run progressively faster in a straight runway as they approach a food reward. Other animal studies followed, documenting a similar pattern in effort towards a goal (for a review see Heilizer, 1977).

More recently, some animal studies have found evidence, at a neurological level, suggesting that the affective system plays a role in generating the goal gradient in effort. Shidara, Aigner, and Richmond (1998) and Shidara and Richmond (2002) monitored the brain activity of monkeys as they exerted effort to reach a reward, and found selective response in the ventral striatum and anterior cingulate, respectively, as visual cues signaled increasing proximity to the reward (distance to the reward was varied randomly over time, so monkeys had to rely on cues to infer current proximity). These structures are believed to be part of a loop between reward expectancy, affective response, and effort. At the same time that the monkeys exhibited increasing activation in these parts of the affective system, they also exhibited a goal gradient, increasing effort and making fewer mistakes on the task as distance to the goal decreased.

See, Heath, and Fox (2003) provides evidence of similar pattern of behavior in humans, in a study using college athletes. In this study, a goal was marked on a 400- 
meter track, and a subject was positioned at one of two distances from the goal. The subject was then instructed to start running at a gradual pace, until hearing a loud noise generated by the experimenters, which could happen at any time. The subject was told that the noise signaled the beginning of a 10 second period, during which they should try as hard as possible to reach the goal line. The treatment variable was the distance remaining to the goal when the noise was produced. Importantly, both groups of subjects heard the noise at a point when the goal was clearly unattainable in 10 seconds time; distances to the goal were clearly marked on the track, and all subjects were aware of relevant world-record times indicating that the goal was impossible. The main finding of the study is that subjects who heard the noise at a closer distance to the goal ran harder than subjects who heard the noise when they were relatively far from the goal, consistent with the goal gradient effect. Notably, subjects were put in a position where they had to make decisions very quickly, and were thus especially likely to be motivated by the fastacting affective system of the brain.

Kivetz, Urminsky, and Zheng (forthcoming) also find behavioral evidence of a goal gradient among humans, but in the domain of consumer choice. In one experiment, people were offered cards allowing them to receive a free coffee after they had purchased nine previous coffees. Consistent with the goal gradient, participants increased the frequency of coffee purchases as distance from the reward decreased. A similar pattern was observed in an online experiment in which participants received a reward after rating a certain number of songs.

A new model of labor supply 
In the remainder of this section we develop a model of labor supply that nests the traditional, cognitive model but also includes affect as another source of motivation. Building on the evidence from psychology and neuroscience surveyed above, we design the model to allow for conflict between cognitive decision-making and affective impulses, and we formalize the affective system in a way that captures the key properties of affective evaluation.

In the spirit of Loewenstein and O'Donoghue (2005) and other “dual-process” models in economics (Thaler and Shefrin, 1981; 1988; Bernheim and Rangel, 2003; 2004; Benhabib and Bisin, 2004; Fudenberg and Levine, 2004), we assume a two-part objective function for the worker. The first part describes the preferences that inform the worker's cognitive decision-making. Exactly as in the standard model of labor supply, this portion of the objective function values income linearly over the course of work period $t$. More formally, net utility in period $t$, from a cognitive perspective, is given by:

$$
U_{t}=w_{t} e_{t}+z_{t}-c\left(e_{t}\right)
$$

Where the utility from an additional dollar of lifetime income, $\lambda$, is assumed to be equal to $1, w_{t}$ is the wage in period $t, z_{t}$ is income from previous periods that is unrelated to current period effort, and $c()$ is a convex function capturing the cost of effort in utility terms. We denote the optimal level of effort from the perspective of the cognitive system as $e_{t}^{C}=\operatorname{argmax} U_{t}$.

The second part of the worker's objective function corresponds to the preferences of the affective system. Consistent with reference-dependence, the affective system's valuation of income over the day is assumed to vary with distance from a daily earnings goal, denoted $r$. Importantly, this valuation is assumed to be nonlinear, in a way that 
reflects increasing arousal as distance to the goal decreases, and dissipation of arousal once earnings have surpassed the goal. We formalize the net benefits of effort in period $t$, to the affective system, as:

$$
v\left(w_{t} e_{t}+z_{t}-r\right)-c\left(e_{t}\right)
$$

The function $v()$ captures the affective system's valuation of income. We assume that $v^{\prime}()$, the additional value to the affective system of an additional dollar of income, is increasing as total daily earnings approach $r$ from below, consistent with increasing arousal. Once total earnings have surpassed $r$, however, $v^{\prime}()$ is assumed to decrease with further earnings, reflecting a dissipation of arousal. Furthermore, we assume that $v^{\prime}(x)>$ $v^{\prime}(y)$ for any $x<r<y$, i.e. the affective value of an additional dollar is always greater when the individual is below the goal, consistent with loss aversion. ${ }^{5}$ We denote the optimal level of effort from the perspective of the affective system as $e_{t}^{A}=\operatorname{argmax} V_{t}$.

Following Loewenstein and O’Donoghue (2005), we combine the cognitive and affective components into a single objective function, and assume that the worker tries to achieve the cognitive optimum, $e^{C}$, in each work period, subject to willpower costs

${ }^{5}$ This final assumption corresponds to the notion of strong loss aversion (Neilson, 2002), and implies a kink in $v()$ at zero. Given these assumptions $v()$ is equivalent to the "Kahneman-Tversky” value function, proposed by Kahneman and Tversky (1979) as a description of reference-dependent evaluation of outcomes. In this sense our model is similar to Wu, Heath, and Larrick (2002), who propose a dynamic, value-function based model of working towards a goal. An important difference is that they assume the individual is completely myopic. We assume that the affective system is myopic, but allow for forward-looking decision making on the part of the cognitive system. 
involved in moving effort away from the affective optimum, $e^{A}$. Willpower costs are denoted $h$ and are assumed to increase linearly in "distance" between the chosen effort level, $e^{*}$, and the effort level preferred by the affective system. We also assume that the worker does not take into account the impact of current effort on willpower costs in future periods. ${ }^{6}$

Having defined the objective function, we can write down the worker's decision problem. In line with our empirical analysis in the next section, we will focus on a worker's effort decisions over the afternoon, conditional on morning earnings. For simplicity we assume that the afternoon has only two periods. In this case the worker's decision problems, in the first and second periods of the afternoon, can be written:

$$
\begin{aligned}
\operatorname{Max}_{e_{1}} Q_{t} & =w_{1} e_{1}+w_{2} e_{2}-c\left(e_{1}\right)-c\left(e_{2}\right)- \\
- & h\left[v\left(w_{1} e_{1}^{A}+z_{1}-r\right)-c\left(e_{1}^{A}\right)-\left(v\left(w_{1} e_{1}+z_{1}-r\right)-c\left(e_{1}\right)\right)\right] \\
\operatorname{Max}_{e_{2}} Q_{t} & =w_{2} e_{2}-c\left(e_{2}\right)- \\
- & h\left[v\left(w_{1} e_{1}^{A}+w_{2} e_{2}^{A}+z_{2}-r\right)-c\left(e_{2}^{A}\right)-\left(v\left(w_{1} e_{1}+w_{2} e_{2}+z_{2}-r\right)-c\left(e_{2}\right)\right)\right]
\end{aligned}
$$

Willpower costs are captured by the terms in brackets, which express the difference between the affective system's objective function, evaluated at the affective optimum, $e^{A}$,

\footnotetext{
${ }^{6}$ This does not mean that the individual is "naïve," ignoring the impact of current effort on the decisions of future selves; the individual still has a strategic interest in encouraging future selves to adhere to current-period preferences. Rather, the assumption is that the individual does not incorporate the willpower costs of future selves directly into the current period utility function, and thus would, if possible, force future selves to exert maximum willpower, without regard for discomfort experienced by future selves.
} 
and the affective system's objective function evaluated at the worker's chosen effort level. Willpower costs are thus equal to zero if the worker complies with the wishes of the affective system, and increase linearly in deviations from $e^{A}$.

The optimal effort levels in period 2 and period 1 are then given by the following first order conditions:

$$
\begin{aligned}
& c^{\prime}\left(e_{1}\right)=w \frac{1+h v^{\prime}\left(w_{1} e_{1}+z_{1}-r\right)+\left[\frac{h\left(1-v^{\prime}\left(w_{1} e_{1}+w_{2} \tilde{e}_{2}+z_{2}-r\right)\right)}{1+h} \frac{\partial \tilde{e}_{2}}{\partial e_{1}}\right]}{1+h} \\
& c^{\prime}\left(e_{2}\right)=w \frac{1+h v^{\prime}\left(w_{1} e_{1}+w_{2} e_{2}+z_{2}-r\right)}{1+h}
\end{aligned}
$$

Where $\tilde{e}_{2}$ is the effort that the period-1 self expects to exert in period 2. A first observation is that affect can lead to either lower or higher effort levels, compared to effort levels predicted by the standard model. One determining factor is quite intuitive, and can be seen by comparing (8) to the condition for optimal effort in the standard, cognitive model. According to (8), effort in period 2 is higher than in a purely cognitive model if the value that the affective system places on an additional dollar of income, $v^{\prime}()$, is greater than 1 , which is the value the cognitive system places on an additional dollar (recall that $\lambda$ was assumed to be equal to 1 ). Similarly, if the affective system cares less about income than the cognitive system, i.e., $v^{\prime}()<1$, effort in period 2 is lower than in a purely cognitive model.

The condition for effort in period 1 is more complicated. The term in brackets in (7) arises because the individual is assumed to be forward-looking and "sophisticated," i.e. to take into account the impact of current effort choices on behavior in period 2 . 
Effort in period 1 has an impact on effort in period 2 by changing distance from the goal, and thus the affective system's valuation of income in the second period. Whether effort in period 1 is higher or lower than effort in the standard model thus depends on two factors: whether the affective system's valuation of income in period 1 is more or less than 1 , and whether the additional sophistication motives captured by the terms in brackets tend to increase or decrease effort in period 1.

Although in general the impact of affect on effort is ambiguous, we now turn to two specific examples in which the affective system in the model leads to a goal gradient, consistent with experiments on task effort. We also show that in each case a windfall gain in the morning, reflected in an increase in $z_{t}$, leads to greater effort in period 1 and lower effort in period 2, a prediction that we will test in the empirical analysis later on. Finally, we explain how an increase in the daily wage could lead to a decrease in total daily effort.

As a first example, suppose the individual is below the goal in both periods of the afternoon, reaching the target only at the very end of the day. Furthermore, assume that the individual is naïve, i.e. does not take into account the impact of current effort on future affective evaluations, so that the bracketed terms in (7) disappear. In this case the model clearly predicts a goal gradient, i.e., $e_{1}<e_{2}$, because the individual is closer to the goal, and $v^{\prime}()$ is larger, in period 2. Now suppose that the individual experiences a windfall gain in the morning, such that the individual is above the goal in period 2. Period 1 effort must be higher than before, because the individual is now relatively closer to the goal in period 1. In period 2, effort is lower than before, because the individual is beyond the goal and the affective valuation of income is lower. Thus the model predicts a 
positive response of effort early in the afternoon, and a negative response later in the afternoon, after a windfall gain in the morning.

The model makes the same prediction in the next example, in which the individual is now assumed to be sophisticated, provided that the affective system places a relatively large value on income, i.e. $v^{\prime}()>1$ in both periods. In this case, sophistication effects reinforce the goal gradient. Intuitively, $v^{\prime}()>1$ implies that the affective system cares "too much" about income in the second period. This gives the first period self a motive to reduce effort in period 1 , in order to increase distance from the goal in period 2 and thus reduce the affective system's valuation of income in the second period. Formally, this result arises because the sign of the product in the brackets in (7) is negative, leading to even lower effort in period 1 compared to period 2. To see this, note that the derivative of $\widetilde{e}_{2}$ with respect to $e_{1}$ is positive, because effort in period 1 moves the individual closer to the goal in period 2, which increases $\tilde{e}_{2}$. Given $v^{\prime}()>1$, the sign of the product is unambiguously negative. Turning to the case where a windfall gain in the morning causes the individual to be above the goal in period 2, sophistication effects reinforce the tendency for effort to increase in period 1 and decrease in period 2. To see this note that the product in brackets is now positive, because the derivative of $\tilde{e}_{2}$ with respect to $e_{1}$ is positive: an increase in $e_{1}$ places the individual farther beyond the goal in period 2 and thus leads to a lower $\tilde{e}_{2}$.

A final noteworthy feature of the model is the predicted response to a wage increase. In line with empirical evidence that workers sometimes reduce total daily effort on high wage days, the model can predict a decrease in total daily effort if the wage goes up. To see this, suppose that on a low wage day the worker is below the goal for the 
whole day. On a high wage day, by contrast, it is easier to reach the goal, say by the second period in the afternoon. As discussed above, switching from being above the goal to being below the goal in period 2 can decrease effort in period 2, because the affective system no longer places a high value on income once the goal is achieved. Although a wage increase tends to encourage higher effort, through the channel of purely financial incentives considered by the cognitive system, and due to the goal gradient in earlier periods of the day, a strong drop in period 2 effort could result in a net drop in total daily effort. The model predicts that the drop in effort is more likely dominate if workers are allowed to quit early, i.e. reduce effort in period 2 all the way to zero, consistent with findings in the empirical literature. E.g. Fehr and Goette (2002) find that a wage increase causes a relatively small decrease in daily effort at a Swiss bicycle messenger firm, where messengers are able to reduce effort, but are not allowed to quit entirely, before the end of their daily shift. Camerer et al. (1997) find a larger decrease in effort among cab drivers, potentially reflecting the greater freedom of cab drivers to quit early.

\section{Data Description and Empirical Design}

\subsection{Data}

In order to test the relevance of affect for labor supply choices in a real work setting, we analyze data from two bicycle-messenger firms operating in the same city, which we will call Firm A and Firm B. Bicycle messenger firms offer same-day, or same-hour delivery of packages, in urban areas where traffic-congested streets make a bicycle the fastest method of delivery. At the firms we study, messengers are paid a simple piece rate, which is a fixed fraction of the price of each delivery (50 percent). Delivery prices vary based 
on the distance the messenger must carry the delivery, how quickly the customer needs the delivery, and the weight of the package.

Bicycle messengers are attractive subjects for the study motivation and effort, because they have substantial discretion over how hard they work, and when, during a workday. Deliveries are announced over the airwaves by a dispatcher, and are heard by all of the company's messengers working that day. Messengers have several ways to vary effort in this setting: they can work hard to finish deliveries quickly, and lobby the dispatcher for more deliveries, or they can make deliveries slowly, and respond slowly to the dispatcher's calls on the radio.

We use the electronic delivery records of Firms A and B to study the effort decisions of individual messengers. These records span several years for each firm, and include all deliveries made by all workers. Crucially, the records include the date, and time of day of each delivery made by a messenger, as well as the price of the delivery. With this information we are able to see the effort profile over the day of each messenger, and study the impact of windfall gains in the morning on effort profiles in the afternoon.

We also conducted a survey with messengers in the same city. ${ }^{7}$ A total of 119 messengers returned completed surveys, giving us a response rate of roughly 60 percent. The survey was administered in two ways: (1) we contacted messenger firms, and arranged to leave the survey in the mailboxes of the messengers at these firms; (2) during the working day, we handed-out surveys to messengers waiting for deliveries at one of several well-known waiting spots. Messengers were paid for completing the survey, and

\footnotetext{
${ }^{7}$ We obtained permission to conduct the survey from the Committee for the Protection of Human Subjects at the University of California, Berkeley.
} 
had a deadline of four weeks to return the survey. Most messengers returned the survey within a few days.

\subsection{Descriptive Statistics}

We begin our analysis with some simple descriptive statistics. These give a sense for the typical working day experienced by a bicycle messenger, and point to the importance of luck for determining a messenger’s daily earnings.

Table 1 describes the length of the working day for a bicycle messenger, in terms of total hours on the job. At both firms, the majority of messengers are on the job for 10 hours, but there appears to be some margin for quitting early or working late: roughly 20 percent work only 9 hours and 20 percent work 11 hours or more. Figure 1 shows the distributions of quitting and starting times at the two firms. The majority of messengers start work between 8:00 and 9:00 am, and 80 percent have started by 10:00 am. In the afternoon, only about 5 percent of messengers have quit by 4:00. Roughly 10 percent quit between 4:00 and 5:00, 40 percent quit between 5:00 and 6:00, and 35 percent quit between 6:00 and 7:00.

Figure 2 shows the distributions of daily earnings for messengers at Firm A and Firm B. Two features of these distributions are noteworthy. First, they are quite similar across firms. Second, daily earnings are highly variable. The standard deviation of daily earnings is $\$ 46.27$ at Firm A and $\$ 50.29$ at Firm B. Morning earnings, not shown, are also similarly variable, with a standard deviation of roughly $\$ 30.00$ at both firms.

There are several possible sources of the variation in earnings for a messenger. In this chapter we are particularly interested in the variation in morning earnings that 
represents windfall gains, or luck. However, some of the variation in earnings is certainly due to day-to-day fluctuations in demand for messenger services, or differences in messenger characteristics. Therefore, to assess the importance of windfall gains for determining a messenger's earnings, we must first remove the variation due to day and messenger effects. Table 2 shows an analysis of variance for morning earnings. The adjusted R-squared statistics indicate that day and messenger effects explain a significant portion of the variation in morning earnings at both firms. However, consistent with an important role for luck in determining morning earnings, there remains substantial unexplained variation. This variation is economically meaningful to messengers, as shown by the fact that the standard deviation of unexplained variance is equivalent to roughly 30 percent of a messenger’s average morning earnings.

There are two important sources of randomness in daily earnings for a bicycle messengers. First, earnings vary with the characteristics of a delivery - the service type, and the pick-up and drop-off zones of the delivery - which are not necessarily correlated with the effort required to make the delivery. For example, two deliveries may involve the same effort, but because one happens to cross the border of a pricing zone in the city, it may generate significantly higher earnings. Messengers also talk about the importance of luck in generating a collection of deliveries that "line up," allowing the messenger to deliver all packages along a roughly linear path rather than having to make significant detours for each one. The second important source of randomness comes from the fact that if one messenger gets a delivery, due to fortunate timing in answering the dispatcher's call, this prevents another messenger from getting the delivery. 


\subsection{Empirical Design}

Our empirical strategy is to test for an impact of windfall gains in the morning on effort in the afternoon. In the standard model, within-day windfall gains should have no impact on effort, because they are trivial relative to lifetime and thus cannot change the marginal valuation of income. On the other hand, if workers attach affective significance to the level of their daily earnings, windfall gains could have an impact on effort. The alternative model formulated in this chapter makes a distinct prediction regarding the impact of a windfall gain in the morning: a worker who had a lucky morning is predicted to work harder than other messengers at the beginning of the afternoon, because they are relatively closer to reaching their goal, and then work less hard than the others towards the end of the day, because they have already surpassed their goal.

Our analysis focuses on the relationship between windfall gains in the morning and afternoon effort. Although we could measure windfall gains in terms of earnings, we will use revenues, which are a simple function of earnings (earnings/0.50) have the advantage that they yield a direct interpretation in terms of benefits for the firm. We calculate a messenger's morning revenues on a particular day by summing the value of all deliveries a messenger completed between the beginning of work and lunchtime.

We measure effort in the afternoon as follows: we follow each messenger working on a particular afternoon for 6 hours, starting at 1:00 pm (6 is the maximum number of hours a messenger works in the afternoon at both firms), and use hourly revenues as an indicator of effort. This creates six measurements of hourly effort for a messenger working on a particular afternoon. If a messenger had zero revenues during an hour, we set effort to zero in that episode. This measure of work effort is the broadest 
possible, and is precisely as standard economic theory suggests it should be. It captures (i) how hard a messenger is working, (ii) whether he is taking breaks during the day, and (iii) when the messenger quits for the day (after the messenger quits, we set effort to zero for the remaining hours in the workday).

We then estimate equations of the form:

$$
e_{i k t}=\gamma^{1} \text { Morning }_{i k t}^{1}+\gamma^{2} \text { Morning }_{i k t}^{2}+. .+\gamma^{6} \text { Morning }_{i k t}^{6}+\beta x_{i t}+a_{i}+d_{t}+\varepsilon_{i k t}
$$

Where $e_{i k t}$ is effort of messenger $i$ at hour $k$ on date $t$. Our coefficients of interest are the $\gamma^{k}$ coefficients: the variable Morning $^{k}$ is the product of morning revenues for the individual and a dummy variable equal to one if it is the $k^{\text {th }}$ hour of the afternoon. We want the $\gamma^{k}$ coefficients to reflect the impact of windfall gains on effort in work hour $k$. For the coefficients to have this interpretation, we need to control for factors that determine variation in morning revenues besides luck.

The vector $x$ consists of time-varying, individual control variables. These include starting hour on day $t$, days of experience at the firm, as well as dummy variables equal to 1 if the messenger worked the day before or the day after date $t$, to control for fatigue spillovers between days. We also include a messenger fixed effect, $a_{i}$, to control for timeinvariant individual characteristics, such as ability, and a fixed effect, $d_{h t}$, which we estimate separately for each day at each firm to control for firm-specific, day-specific shocks, such as weather.

With these controls in place, $\gamma^{k}$ indicates by how much the messenger changed effort in work hour $k$ in response to an increase in windfall gains in the morning. The model incorporating affect predicts positive values for $\gamma^{k}$ early in the afternoon and 
potentially negative values for $\gamma k$ later in the day. The prediction of the standard model is that $\gamma^{k}$ should be zero for all hours.

One caveat is that we might not eliminate all factors driving morning revenues besides luck. If a portion of the variation in morning earnings is still positively correlated with effort in the morning, and morning effort causes fatigue and makes it harder to work in the afternoon, then the standard model could predict negative $\gamma k$ 's in the afternoon. ${ }^{8}$ This is unlikely given our controls, however, and given that messengers typically take a lunch break and have the opportunity to rest, minimizing the relevance of fatigue effects from the morning. Also, this channel should not lead to the reversal in correlation predicted by the alternative model; if workers with high morning earnings are fatigued they might work less hard in the afternoon, but the standard model does not predict a goal gradient effect, i.e. $\not k$ 's that are increasing over the first portion of the afternoon. Thus a goal gradient is an indication that affect, and not fatigue, explains the response to changes in morning earnings.

We estimated our baseline regression equation using OLS. An important issue is how one should calculate the standard errors of the estimated coefficients. Given the hourly frequency of our measures, there are various ways in which $\varepsilon_{i t}$, the error term, departs from the i.i.d. assumption of OLS. First, the way we construct our measure of

${ }^{8}$ Fatigue spillovers could be incorporated by making the slope of the cost function for effort in period $t$ an increasing function of effort exerted in previous periods, as we do in Goette and Huffman (2005). 
labor supply makes the error term inherently heteroskedastic. ${ }^{9}$ We correct for this by estimating robust standard errors. Second, there are two potential sources of correlation between the error terms. Within a given day, if one messenger was assigned a delivery, another messenger will end up with one less delivery. This leads to negative correlation of the residuals within a day, rendering OLS standard errors too large. On the other hand, there could be positive correlation in $\varepsilon_{i t}$ for observations coming from a given messenger, rendering OLS standard errors too small (see Bertrand, Duflo and Mullainathan, 2004, for an extensive discussion). As a consequence, we estimate two sets of standard errors. One set is adjusted for "clustering," or correlation, in the error term across days. Because this ignores the (potentially) positive correlation within individuals, we consider these standard errors the lower bounds. The other is adjusted for clustering on messengers. We consider this the upper bound on the standard errors, because it ignores the (potentially) negative correlation within days. However, our basic conclusions do not depend on which adjustment of standard errors we use.

\section{Results}

\subsection{Analysis of Delivery Records}

Figure 3 summarizes the results from our regression analysis using the delivery records of firms A and B. The figure plots the values of the $\gamma^{k}$ regression coefficients, multiplied by 50 to illustrate the impact of a $\$ 50$ windfall gain. All coefficients are

\footnotetext{
${ }^{9}$ Because our dependent variable is bounded below by zero, this necessarily implies that the variance of the error term differs between observations.
} 
statistically significant at the 1 percent level, except for the coefficient for the first hour of the afternoon at Firm A, which is not significant.

Figure 3 shows that windfall gains in the morning have a statistically significant impact on the effort profile in the afternoon, contrary to the predictions of the standard, cognitive model of labor supply. On the other hand, the response of effort to the windfall gain is consistent with messengers attaching affective significance to a daily earnings goal. As predicted by the alternative model of labor supply, a messenger with a windfall gain works harder than other messengers in the first part of the afternoon, but less hard later in the day. Furthermore, the fact that the relative difference in effort is increasing over the first few hours is consistent with the goal gradient prediction of the model and not with an explanation based on fatigue from the morning. ${ }^{10}$

Our results are also consistent with previous studies, which conclude that daily earnings goals influence the effort decisions of piece rate workers. These studies have focused on the impact of day-to-day variation in wages on total daily effort, and have found that higher wages lead to lower daily effort, consistent with workers achieving a daily earnings goal more quickly under the high wage (e.g. Camerer et al., 1997, Chou,

${ }^{10}$ These findings are also broadly consistent with the predictions of the referencedependent model of labor supply in Koszegi and Rabin (2005), which predicts that an unexpected increase in morning earnings can lead to a drop in effort in the afternoon. However, their model has only two periods, morning and afternoon, and thus cannot predict the goal gradient that we observe. This reflects the different focus of their research, on modeling the role of expectations in determining the reference point, rather than the role of affect as a source of motivation to work towards a reference point. 
2003; Fehr and Goette, 2002). With the exception of Goette and Huffman (2005), however, these studies have not been able to observe within-day effort profiles and thus have not been able to test for the goal gradient effect. Goette and Huffman (2005) study the impact of exogenous increases in the piece rates at two bicycle messenger firms and find that messengers on the high piece rate work harder earlier in the day, but less hard later in the day, than messengers of the low piece rate, consistent with the evidence on the goal gradient effect presented in this chapter.

\subsection{Survey evidence}

An advantage of conducting a survey is that we can ask messengers directly whether they have earnings goals that are relevant during the workday. Accordingly the survey included the following question:

After earning ___ dollars during the day, it feels less urgent to earn another dollar (if this question does not apply to you, answer with N.A.)"

Of the messengers surveyed, 73 percent responded that they have such a dollar amount in mind during the day. The survey also asked, "What is the minimum amount you need to earn in a day, to make it worthwhile to come to work?” With only a few exceptions, this minimum amount is below the amount a messenger reports in the first question, consistent with the first question measuring an earnings goal that is distinct from a daily minimum.

Another question in the survey presented respondents with a hypothetical scenario, which was designed to correspond to our analysis of the delivery records. The question describes two scenarios: in one scenario, the messenger has had a "good" 
morning, earning much more than average; in the other scenario the messenger has had a "slow" morning, earning much less than average. The question states that the messenger worked equally hard in the two scenarios, and that in either case the afternoon is expected to be good. This establishes a difference in earnings across the scenarios due to windfall gains, and not due to effort. The question then asks the messenger to fill in the following statement, using a scale that goes from "much less” to "much more:”

"After the slow morning, I care about earning another dollar, relative to after the good morning.”

In the survey responses, 18 percent of messengers say they care the same, 72 percent say they care more, and 10 percent say they care less about earning another dollar after the slow morning. This is consistent with the majority of the messengers being loss averse around a daily income goal: a good morning puts a worker close to their daily target and leads to lower marginal utility of income in the afternoon. Because the question keeps morning effort constant across both scenarios, fatigue does not appear to explain why messengers say they would work less hard after a good morning.

\section{Conclusion}

The standard economic model of labor supply assumes that a worker decides how hard to work, and when, based on a purely cognitive calculation of costs and benefits. By contrast, this chapter argues that affect is an additional, important source of motivation in the workplace. Building on evidence from neuroscience, we propose a new, dual-process model of labor supply, which maintains the standard assumption in economics, that the worker's cognitive processes are sophisticated and forward-looking, but allows for 
circumstances in which affective processes can override cognitive priorities and distort the worker's effort profile. In particular, the worker's daily performance is assumed to have an affective significance, depending on how it compares to a personal goal or reference level. Consistent with evidence from neuroscience, the affective system is assumed to value effort more highly when the worker has not yet achieved the goal. Furthermore, the affective system is assumed to become increasingly aroused as the goal becomes more immediate, leading to the prediction of an increasing effort profile, or goal gradient, leading up to a goal.

The alternative model is able to explain important facts about effort decisions in the workplace, which are difficult to explain from a purely cognitive perspective. One example is the new evidence of a goal gradient presented in this chapter. Using data on the within-day effort profiles of bicycle messengers, we show that a windfall gain in morning earnings causes a messenger to work harder in the first portion of the afternoon, relative to other messengers, but less hard later in the afternoon. This pattern is inconsistent with a purely cognitive model, because a windfall gain in the morning does not affect the financial incentives to work in the afternoon. On the other hand, the pattern is consistent with the lucky morning pushing the messenger closer to a daily earnings goal, triggering the goal gradient and leading to more intense effort early in the afternoon. Later in the afternoon, when other messengers are still approaching their goals, the lucky messenger may have already surpassed the goal and thus work less hard. Another example is the important finding in previous studies that a worker's total daily effort is often unchanged, or even decreases, in response to a temporary increase in the wage. This contradicts a central prediction of a purely cognitive model that a worker should work 
harder when financial incentives are high. The alternative model can explain this perverse effect of financial incentives, however, because it allows for affective, as well as financial valuation of effort: a higher wage allows a worker to reach a daily earnings goal more quickly, and thus causes the affective valuation of effort to drop earlier in the day. If affect was a sufficiently important component of the worker's motivation to begin with, reaching the goal earlier can lead to a net drop in total daily effort.

The broader theme of this volume is whether affect leads to better or worse decisions. The answer to this question depends partly on the benchmark used. In our model, affect causes the worker to work too hard when the goal is close, and not hard enough when the goal is surpassed, compared to a purely cognitive perspective. On the other hand, it is not clear whether a purely cognitive model is the correct benchmark. If the worker suffers from self-control problems, e.g. an urge to take a break at a favorite bar during the day, affective engagement in a daily earnings goal could tend to improve overall productivity and lead to better labor supply decisions. This line of argument raises interesting questions, about whether individuals consciously use goals, and affect, as a device for overcoming self-control problems. Another question is whether incomemaximization is a sufficient criterion for evaluating a good decision, or whether the priorities of the affective system should be given some weight as well.

From the perspective of the employer, affect can be productive if it leads to greater motivation than is achievable by financial incentives alone. On the other hand, if worker's goals are not ambitious enough, affect can be counterproductive. Thus our findings suggest that it is in the interest of employers to identify and perhaps influence the goals and affective engagement of workers. 


\section{References}

Baumeister, Roy F. and Kathleen D. Vohs (2003). "Willpower, Choice, and SelfControl,” in George Loewenstein, Daniel Read and Roy F. Baumeister, eds., Time and Decision: Economic and Psychological Perspectives on Intertemporal Choice. New York: Russell Sage Foundation, 201-216.

Benhabib, Jesand Alberto Bisin (2004). "Modelling Internal Commitment Mechanisms and Self-Control: A Neuroeconomics Approach to Consumption-Saving Decisions.” Mimeo, New York University.

Bernheim, B. Douglas and Antonio Rangel (2003). "Emotions, Cognition, and Savings: Theory and Policy.” Mimeo, Stanford University.

Bernheim, B. Douglas and Antonio Rangel (2004). "Addiction and Cue-Triggered Decision Processes.” American Economic Review, 94(5), 1558-1590.

Bertrand, Marianne; Duflo, Esther and Mullainathan, Sendhil (2004). "How Much Should We Trust Differences-in-Differences Estimates?” Quarterly Journal of Economics, 119(1), 249-75.

Camerer, Colin, Linda Babcock, George Loewenstein and Richard Thaler (1997). "Labor Supply of New York City Cabdrivers: One Day at a Time.” Quarterly Journal of Economics 112(2), 407-41.

Chen, Keith M., Venkat Lakshminarayanan, and Laurie Santos (2005). “The Evolution of Our Preferences: Evidence form Capuchin Monkey Trading Behavior,” unpublished manuscript, Yale university.

Chou, Yuan K. (2002). "Testing Alternative Models of Labor Supply: Evidence from Cab Drivers in Singapore." The Singapore Economic Review 47(1), pp. 17 - 47.

Cohen, Jonathan D. (2005). “The Vulcanization of the Human Brain: A Neural Perspective on Interactions Between Cognition and Affect and Optimality in Decision Making.” Working Paper, Department of Psychology, Princeton University.

Farber, Henry (2005) "Is Tomorrow Another Day? The Labor Supply of New York City Cab Drivers,” Journal of Political Economy, 113, 46-82.

Fehr, Ernst and Lorenz Goette (2002). “Do Workers work more when Wages are High? Evidence from a Randomized Field Experiment.” IEW Working Paper 144.

Goette, Lorenz and David Huffman (2005) "Incentives and Within-Day Effort Profiles: Evidence from Natural Experiments with Bicycle Messengers, unpublished manuscript, Univ. of Zurich. 
Goette, Lorenz, David Huffman and Ernst Fehr (2004) "Loss Aversion and Labor Supply,” Journal of the European Economic Association, 2(2-3), 216-228.

Heath, Chip, Richard Larrick, and George Wu (1999). “Goals as Reference Points.” Cognitive Psychology 38, pp. 79-109.

Heilizer, Fred (1997) “A Review of Theory and Research on the Assumptions of Miller's Response Competitions Model: Response Gradients,” The Journal of General Psychology, 97, 17-71.

Kahneman, Daniel and Amos Tversky (1979) "Prospect Theory: An Analysis of Decisions Under Risk,” Econometrica, 47, 263-291.

Kivetz, Ran, Oleg Urminsky, and Yuhuang Zheng (2005) “The Goal Gradient Hypothesis Resurrected: Purchase Acceleration, Illusionary Goal Progress, and Customer Retention,” forthcoming in the Journal of Marketing Research.

Koszegi, Botond and Matthew Rabing (2005) “A Model of Reference-Dependent Preferences,” unpublished manuscript, UC Berkeley.

LeDoux, Joseph E. (1996). The Emotional Brain: The Mysterious Underpinnings of Emotional Life. New York, NY: Simon and Schuster.

Loewenstein and O’Donoghue (2005). “Animal Spirits: Affective and Deliberative Processes in Human Behavior,” unpublished manuscript, Cornell University.

MacLean, Paul D. (1990). The Triune Brain in Evolution: Role in Paleocerebral Function. New York: Plenum.

Manuck, Stephen B., Janine D. Flory, Matthew F. Muldoon, and Robert E. Ferrell (2003). “A Neurobiology of Intertemporal Choice,” in George Loewenstein, Daniel Read and Roy F. Baumeister, eds., Time and Decision: Economic and Psychological Perspectives on Intertemporal Choice. New York: Russell Sage Foundation, 139172.

Massey, Douglas S. (2002) “A Brief History of Human Society: The Origin and Role of Affect in Social Life.” American Sociological Review, 67, (1), 1-29.

McClure, Samuel M., David Laibson, George Loewenstein, and Jonathan D. Cohen (2004). "Separate Neural Systems Value Immediate and Delayed Monetary Rewards.” Science, 306(Oct 15), 503-507.

Metcalfe, Janet and Walter Mischel (1999). “A Hot/Cool-System Analysis of Delay of Gratification: Dynamics of Willpower.” Psychological Review 106(1), 3-19. 
Mischel, Walter, Ebbe B. Ebbesen, and Antonette Zeiss (1972). “Cognitive and Attentional Mechanisms in Delay of Gratification.” Journal of Personality and Social Pychology, 21(2), 204-218.

Mischel, Walter, Ozlem Ayduk, and Rodolfo Mendoza-Denton (2003). "Sustaining Delay of Gratification over Time: A Hot-Cool Systems Perspective,” in George Loewenstein, Daniel Read and Roy F. Baumeister, eds., Time and Decision: Economic and Psychological Perspectives on Intertemporal Choice. New York: Russell Sage Foundation, 175-200.

Mischel, Walter, Yuichi Shoda, and Monica L. Rodriguez (1989). "Delay of Gratification in Children.” Science, 244(4907), 933-938.

Nielson, William S. (2002) "Comparative Risk Sensitivity with Reference-Dependent Preferences,” The Journal of Risk and Uncertainty, 24(2),131-42.

See, Kelly E., Chip Heath and Craig Fox (2003) "Motivating individual performance with challenging goals: Is it better to stretch a little or a lot?” Working Paper, Fuqua School of Business.

Shidara, Munetaka, Thomas G. Aigner, and Barry J. Richmond (1998) “Neuronal Signals in the Monkey Ventral Striatum Related to Progress through a Predictable Series of Trials,” The Journal of Neuroscience, 18(7), 2613-2625.

Shidara, Muntetaka and Barry J. Richmond (2002) “Anterior Singulate: Single Neuronal Signals related to Degreee of Reward Expectancy,” Science, 296, 1709-1711.

Shiv, Baba, George Loewenstein, Antoine Bechara, Hanna Damasio, and Antonio Damasio (2005). "Investment Behavior and the Dark Side of Affect." Mimeo, University of Iowa.

Thaler, Richard H. and Hersh M. Shefrin (1981). “An Economic Theory of SelfControl.” Journal of Political Economy, 89(2), 392-406.

Tversky, Amos and Daniel Kahneman (2000). Choices, Values, and Frames. Cambridge, MA: Cambridge University Press.

Wu, George, Chip Heath, and Richard Larrick (2002) “A Value-Function Based Model of Goal Behavior," unpublished manuscript, Univ. of Chicago Graduate School of Business. 


\section{Figure 1}
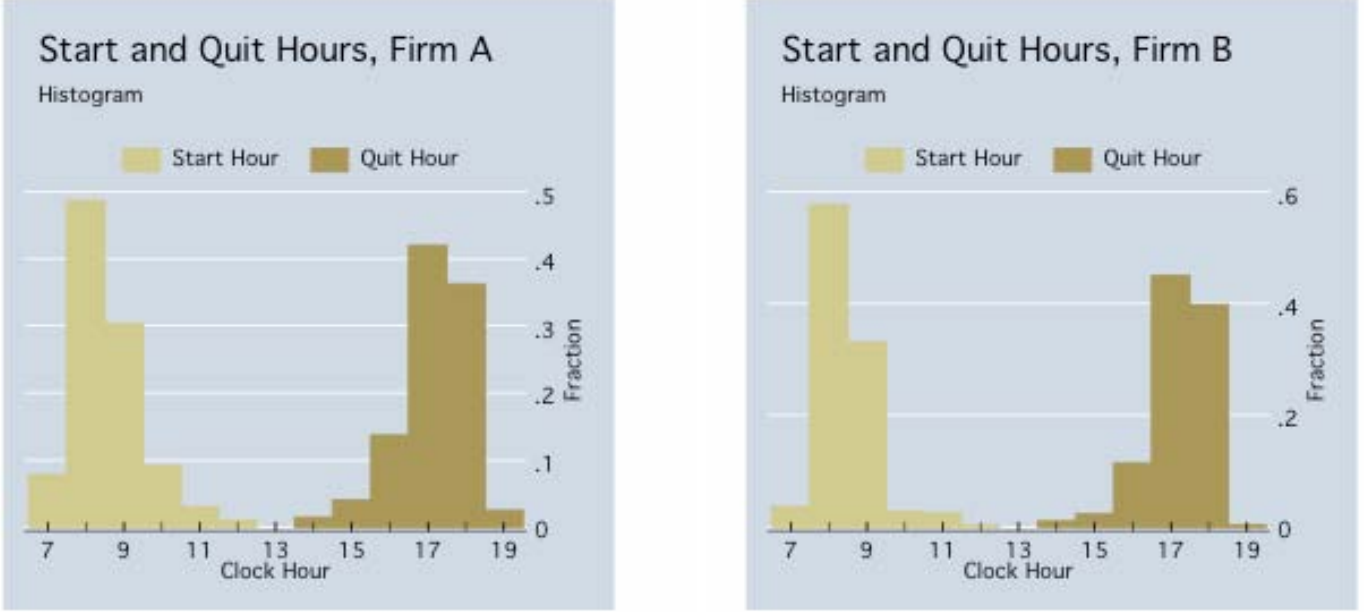

Figure 2
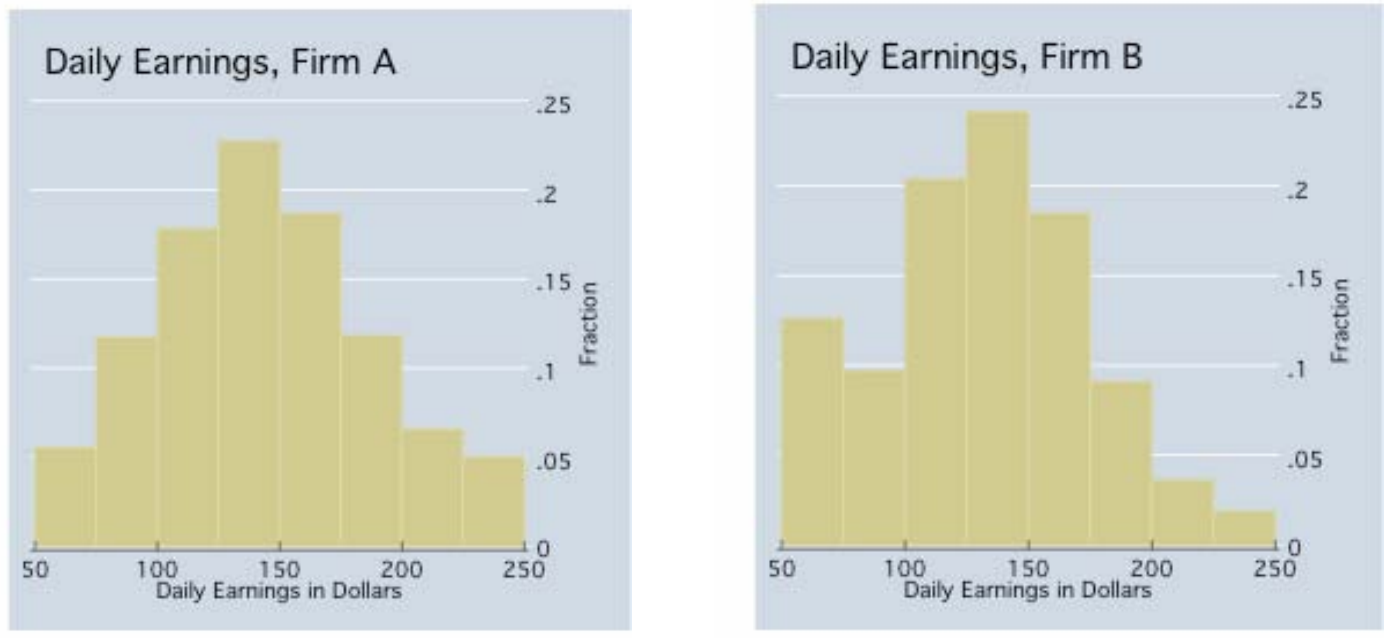


\section{Figure 3}

Effort over Time: The I mpact of a \$ 50 increase in morning revenues $(+/-2 *$ s.e. of estimate)

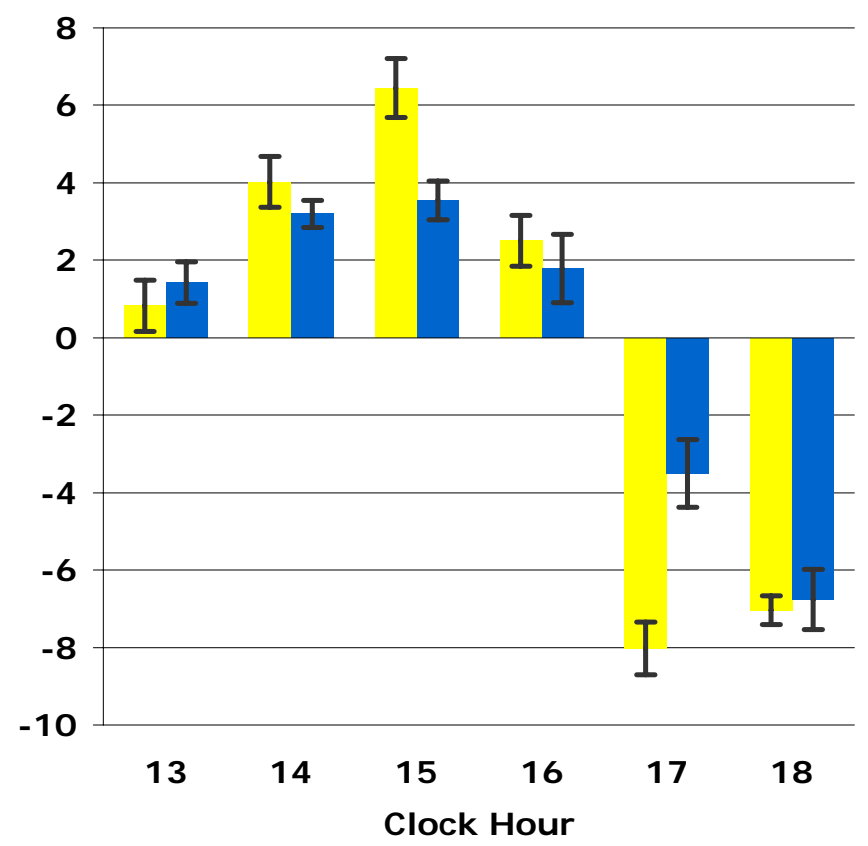

Firm B Firm A

Results from regression of hourly revenues

Mean revenues appr. $\$ 16$ / hour.

Controls for (i) Messenger fixed effects, (ii) Firm* day fixed effects, (iii) Start hour.

Standard errors adjusted for clustering on messenger. 
Table 1

Hours on the Job

\begin{tabular}{cccc}
\hline \hline \multicolumn{2}{c}{ Firm A } & \multicolumn{2}{c}{ Firm B } \\
\hline $6-$ & $1.39 \%$ & $6-$ & $0.94 \%$ \\
7 & $3.30 \%$ & 7 & $1.45 \%$ \\
8 & $8.73 \%$ & 8 & $4.55 \%$ \\
9 & $24.39 \%$ & 9 & $20.34 \%$ \\
10 & $40.34 \%$ & 10 & $53.63 \%$ \\
$11+$ & $21.85 \%$ & $11+$ & $19.00 \%$ \\
\hline
\end{tabular}

Table 2

ANOVA for Morning Earnings

\begin{tabular}{|c|c|c|}
\hline & Firm A & Firm B \\
\hline & \multicolumn{2}{|c|}{ Adjusted R-squared } \\
\hline Date Fixed Effects & .1238 & .1000 \\
\hline $\begin{array}{l}\text { Date and Messenger Fixed } \\
\text { Effects }\end{array}$ & .3106 & .5983 \\
\hline $\begin{array}{c}\text { SD of Unexplained } \\
\text { Variance } \\
\text { (as \% of average morning } \\
\text { earnings) }\end{array}$ & $33.04 \%$ & $28.69 \%$ \\
\hline Observations & 21,474 & 22,866 \\
\hline
\end{tabular}

